Research Article

\title{
Is Organizing Knowledge Effective in Primary Education?
}

\author{
Marisol Cueli, ${ }^{1}$ Ana Isabel Álvarez, ${ }^{2}$ Stephen Loew, ${ }^{3}$ Paloma González-Castro, ${ }^{1}$ \\ and Celestino Rodríguez $\mathbb{B D}^{1}$
}

${ }^{1}$ Department of Psychology, University of Oviedo, Oviedo, Spain

${ }^{2}$ Department of English, French and German Philology, University of Oviedo, Oviedo, Spain

${ }^{3}$ School of Psychology, University of New England, Armidale NSW, Australia

Correspondence should be addressed to Celestino Rodríguez; rodriguezcelestino@uniovi.es

Received 5 April 2020; Revised 20 July 2020; Accepted 27 July 2020; Published 12 August 2020

Academic Editor: Paul S. Szalay

Copyright (C) 2020 Marisol Cueli et al. This is an open access article distributed under the Creative Commons Attribution License, which permits unrestricted use, distribution, and reproduction in any medium, provided the original work is properly cited.

The acquisition of reading comprehension abilities and written expression is one of the key factors among learning processes in which students show many difficulties. For this reason, it is necessary to implement effective intervention strategies from early school years. The program EPI.com is aimed at improving lexical, semantic, and syntactic processes related to the reading process. This work aims to analyze the efficiency of EPI.com in years 1\&2 of Primary Education. Participants in the research were 62 students (ages 6-8), who were assigned to an Experimental Group (EG; 38 students receiving the EPI.com intervention) and a Control Group (CG; 24 following traditional teaching and learning methods). The Illinois Test of Psycholinguistic Abilities and the Peabody test were applied before and after the intervention was carried out. Results showed that the strategy was effective in EG in improving the psycholinguistic aspects measured by the ITPA, with better results in the variables related to syntactic and lexical processing. Taking the results into account, it was concluded that EPI.com allows students to improve the abilities relating to reading skills. Also, the results highlight the need to incorporate interventions aimed at favoring maturation in some key aspects at early ages.

\section{Introduction}

The acquisition of abilities like reading comprehension and written expression are one of the main aims of education [1]. However, and despite the relevance of these abilities, many students show difficulties in such an important area for academic success [2]. Failures at this level are mainly detected in the school context, hence the relevance of observing possible difficulties among students from an early age, in order to implement strategies that will allow for stimulation of the reading process. Consequently, the objective of the present study is to analyze the benefits brought about by the program EPI.com, aimed at improving instrumental abilities form early ages. In particular, the ages under analysis were 6 to 8 (years $1 \& 2$ in Primary Education).

International reports aimed to analyze reading comprehension abilities, such as PISA (Program for International Student Assessment; Organisation for Economic Cooperation and Development) or PIRLS (Progress in
International Reading Literacy Study; International Association for the Evaluation of Educational Achievement) point to relevant difficulties in reading comprehension among Spanish students, with results in both tests that are below average. In this respect, preliminary reports by the Spanish Ministry of Education and Vocational Training [3] on the PISA 2018 survey, which had reading comprehension as the main competence under evaluation, show that students declare to read less for pleasure (5\% less than in previous editions) and that, in 2018, more students considered reading as "a waste of time." On the other hand, PIRLS 2016 [4] assessed trends in reading comprehension among students in Year 4 of Primary Education (ages 9-10). Results showed that Spanish students scored 528, below the OCDE average (540) and the EU average (539).

This is not only found among students in Spain. For example, $15 \%$ of 7 -year-olds in England do not meet the standards in the National Curriculum and 13\% of Secondary Education students read below expectations [5]. Also, PIRLS 
2011 results indicated that an important percentage of European students do not reach a satisfactory level of reading. Specifically, around a $20 \%$ of the students ( $4^{\text {th }}$ grade) in the European countries showed low reading literacy skills [6].

In sum, international reports as PIRLS, highlight that a large number of students do not reach optimal levels in reading abilities. Furthermore, an important percentage of the students can have specific difficulties in this area (e.g., [7]). The fifth version of the Diagnostic and Statistical Manual of Mental Disorders [8] includes Specific Learning Disorders as a neurodevelopmental disorder that begins during school-age and is characterized by a failure in educational skills, which are significantly lower than expected according to age in several areas, including reading, writing, mathematics, listening, speaking, and reasoning. Specifically, the Specific Learning Disorder with Impairment in Reading includes possible deficits in (a) word reading accuracy; (b), reading rate or fluency; or (c) reading comprehension.

Given that reading difficulties can relate to different factors (reading accuracy, associated with lexical processing, or reading comprehension, associated with syntactic and semantic processing), the estimation of the prevalence ranges between 5 and $15 \%$ of students [7, 8]. Lirola [9] focuses on the percentage of students with special educational needs in Spain in the period between 2011/12 and $2018 / 19$ and finds that the presence of learning difficulties increases from $28 \%$ to $41 \%$. However, resources devoted to this group of students are scarce, and, technologically, there is a limited usage of strategies based on successful methodologies: nonetheless, taking into account the fact that the development of reading fluency and reading comprehension begins at an early age [10], it is necessary to implement strategies to improve reading skills form the earliest school years.

In order to tackle this difficulty, previous research has tried to determine the most adequate methodologies for a specific intervention with these deficits or problems [10-12]. Watson et al. [13] showed that, in furtherance of understanding written language, students must be able to draw inferences and build a "mental model" representing the content of the text. Swanson et al. [14] observed that students required structured instruction in the use of strategies and benefit from explicit instruction methodologies.

According to Ponce et al. [12], a strategy is an action or a sequence of systematic steps that allow students to obtain key information from a text and facilitate its comprehension. Cognitive Reading strategies aim at supporting readers in the selection, organization, interpretation, and comprehension of texts [15]. In doing so, students must have good knowledge of how the strategies work and when to implement those. To this aim, strategies must be explicitly taught for a long period [13], above all, because learning them is not something all students do in an incidental or causal way [12].

Mayer [11] indicates that reading comprehension strategies can be categorized into levels in accordance with the cognitive processes that they try to improve. The SOI
(Selection, Organisation, and Integration) model by Mayer [11] suggests that comprehension strategies may be classified according to three different cognitive processes: selecting information (paying attention to relevant content), organizing (constructing a coherent structure), and integrating information (as related to previous knowledge). In order to reach those three cognitive processes, explicit instruction strategies must be implemented.

In this sense, Álvarez and Soler [16] developed the strategy Hypertexto, in which students relate new information to the one they already may have, readjusting and rebuilding knowledge throughout the process [17]. Hypertextos are graphic organizers of knowledge, whose parts relate to each other through significant links and whose syntactic structure is determined by a subject-some previously known concept or concepts-a verb relating the information and a complement showing the subsequent concept or concepts [16]. Unlike other concept maps, compliance with a set of rules is required in building Hypertexto, among which are the three main rules in Mayer's SOI model: (a) Hypertexto splits into only two branches (the left branch defines and the right branch gives further information, thus favoring the organization of information); (b) key content is highlighted in boluses (a selection of relevant information); (c) linking nodes contain verbs which allow for readers to establish significant relations among contents (integration of information).

Previous studies have shown that organizers of knowledge as graphic organizers allow improving psycholinguistic aspects like semantic process (e.g., [12, 18]). Moore and Readence [19] found that graphic organizers had positive effects on comprehension (semantic and syntactic processes). In addition, Ilter [20] indicated that the use of graphic organizers improved word recognition (related to lexical processes) in students between 10 and 11 years, and Kim et al. [21] showed that graphic organizers enhance reading comprehension among students with learning disabilities. Also, Nesbit and Adesope [22] highlighted that students who use concept maps may be better able to identify the internal connections among concepts presented in a text (related to the syntactical processes). Taking the results in the literature into account, the developers of Hypertexto aimed it at improving psycholinguistic aspects, like lexical processing (main ideas are highlighted in the boluses), semantical processing (contents are significantly related to one another, which favours their being understood), and syntactic processing (every part of the organizational grid requires some punctuation symbol). An example of Hypertexto can be seen in Figure 1.

The implementation of Hypertexto usually begins in year 3 of Primary School and continues during Secondary Education, since that is a moment when the amount of content to be learnt requires strategies of representation and organization for a better comprehension of information. However, it is in the earliest years of school instruction that most learning difficulties appear and when intervention strategies can bring greater benefits to students [23]. The adaptation of Hypertexto for Early Years and for the first stage of Primary Education was carried out in the computerized tool EPI.com 


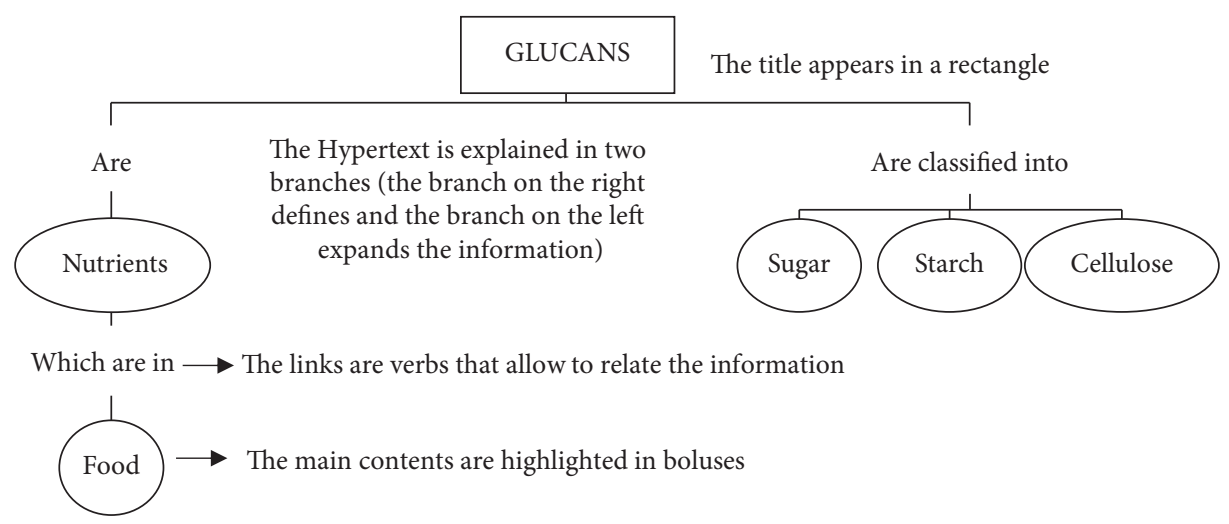

FIgURE 1: Example of Hypertexto and the rules for its elaboration.

$[24,25]$, which was developed with the aim of stimulating psycholinguistic abilities (lexical, syntactic, and semantic processing).

According to Sung et al. [26], difficulties in the application of learning strategies for reading in classrooms may be reduced with the aid of Information Technology. Authors point out several advantages of incorporating computerized systems when teaching to read (e.g., [27]). For example, these systems may provide immediate individual feedback, allowing students to control their learning rate, and, with them, reading motivation is reinforced by means of the different representations. In this sense, Sung et al. [26] found that, with the use of a strategic computerized programme based on Mayer's SOI model, students in Year 6 showed a significant improvement in their effective reading comprehension strategies.

Likewise, Tyler et al. [5] undertook an intervention on 51 students, aged 6-7, with an individually adapted online reading program (Headsprout Early Reading; HER) which includes 80 twenty-minute sessions. Significant differences were found between the group under instruction and the one who did not follow the program. Results showed that using the program rendered positive effects on reading abilities.

Considering the fact that reading is a key factor in the learning process, on which it is advisable to intervene during the early schooling period [18] and also the possibilities brought about by new technologies [26], the present study is aimed at stimulating psycholinguistic aspects by using the program EPI.com with students in years $1 \& 2$ of Primary Education. Two specific objectives have been set: first, to analyze the benefits brought by the strategy to psycholinguistic (lexical, semantic, and syntactic processing) and verbal aspects; second, to analyze those benefits according to the school years (1\&2 of Primary Education). The hypothesis raised is that students working with the program EPI.com will reach better results in the psycholinguistic and verbal aspects assessed.

\section{Materials and Methods}

2.1. Participants. Participants in the research were 62 students, 30 girls, and 32 boys, aged 6 to 7 years old $(M=6.887$, $\mathrm{SD}=0.564)$ and with an average IQ of $102.94(\mathrm{SD}=10.88)$ measured with the Raven's Progressive Matrices Test (SPM form; [28]). All of them were attending years $1 \& 2$ of Primary Education at two schools in the Principality of Asturias (Spain). The schools were located in an urban area and the family profile was characterized by a medium-high socioeconomic level. The schools were selected using convenience sampling as a function of availability and accessibility and were randomly assigned to an experimental condition: Experimental Group (EG; $n=38$, receiving the EPI.com intervention) and Control Group (CG; $n=24$, following traditional teaching and learning methods). The final sample comprised 2 classes in the EG and 2 classes in the CG.

In order to analyze profiles according to students' age, the sample is classified into two groups according to academic years: Year $1(n=30)$ and Year $2(n=32)$.

Analyses showed no statistically relevant differences according to age $F(1,60)=0.50, p=0.823, \eta_{p}^{2}=0.001$, nor gender $\chi^{2}(1)=0.065, p=0.799$, in the selected sample. Differences according to IQ $F(1,60)=0.626, p=0.432$, $\eta_{p}^{2}=0.010$ between both conditions (EG \& CG) were not statistically significant.

2.2. Instruments. Aiming at the above-mentioned objective, a number of variables relating to students' psychological variables were evaluated by means of the Illinois Test of Psycholinguistic Abilities (ITPA) [29, 30]. Furthermore, in order to analyze verbal aspects, the Peabody test [24] was used.

The PEABODY Picture Vocabulary Test [31] is meant to be used with children aged 2 to 5 and up and can also be implemented with adults. Verbal aspects are assessed in 10-20 minutes by means of the test, which contains 192 flashcards, showing four images each. Users are asked to indicate which picture best represents the meaning of a given word. The manual of the test provides a Cronbach's alpha near 0.90 , ranging from 0.80 to 0.99 . In the present study, the Cronbach alpha was 0.975 .

The Illinois Test of Psycholinguistic Abilities ITPA $[29,30]$ is an assessment tool for psycholinguistic functions. Specifically, there are 11 variables under analysis in the ITPA: auditory comprehension, visual comprehension, 
auditory association, visual association, verbal expression, motor expression, grammatical integration, visual integration, auditory integration, sequential auditory memory, and sequential visual-motor memory. All the variables analyzed relate to the three types of processing (association and expression are associated with the lexical level; comprehension with the semantic levels; and integration with the syntactic level). The reliability index of the original version of the test is between 0.74 and 0.90 . In the present study, the Cronbach alpha was 0.973 in the pretest and 0.972 in the posttest, with McDonald $\omega$ of 0.993 y 0.992 for each [32].

2.3. Intervention Tool. The computerized tool EPI.com $[24,25]$ results from an adaptation for early ages of the program Hypertexto [16]. It aims at activating information processing by stimulating psycholinguistic abilities linked to lexical, semantic, and syntactic processing. Specifically, the strategy consists of transforming linear messages into Hypertexto structures in which students select, relate, and transmit the information, thus reaching a better comprehension and processing of the information. As shown in Figure 2, the computerized tool EPI.com provides three structures, or networks, for the organization of linear messages: 1-1 structures (one item, or bolus, on each Hypertexto branch), 1-2 structures (a single bolus to the left and two on the right-hand branch) 1-3 structures: one bolus on the left branch and three on the right-hand branch).

EPI.com fosters this transformation by integrating three crucial aspects for comprehension: representing, organizing, and integrating information. The representation of information begins in EPI.com with basic messages, presented by using images alone (iconic representation), with images associated with words (combined representation), or with words alone (symbolic representation). The choice of one or another form of representation depends on the students' age and competence (e.g., iconic representation is aimed at students aged 3-5, combined representation for those aged $5-6$, and symbolic representation will be used with students aged 6 and up).

The tool presents 90 activities intended for the development of semantic processing (reading comprehension), syntactic processing (written expression), and lexical processing (reading routes), that is, of instrumental ability maturity. The activities address contents that are stated in the Spanish official curriculum for the students' age group (e.g., body and food, family, transport, animals, and seasons).

All the activities are carried out following the same threestep sequence: (1) the starting point is a linear message, in which information may have an iconic, combined, or symbolic representation. (2) Users are first asked to place all elements of the linear message into a Hypertexto (the title in the rectangle, contents in the boluses, and pictograms at the links). These links are always the same: to define: is, is for, is part of; and to expand: has, is for, is in. All these verbs have been linked to a pictogram in EPI.com. (3) Once the Hypertexto has been completed, users must turn it back into a linear message, so as to facilitate the reversibility of the process (Figure 3).
2.4. Procedure. After permission from school authorities was obtained and having also obtained consent from the children's parents and/or legal guards, pretest information was collected (roughly 60 minutes were spent per student). Students participated voluntarily, and confidentiality of the data obtained was granted at all times. Two collaborating specialists, who had previously been trained, carried out pretest and posttest evaluation.

After pretest evaluation, the tool was applied in the EG. A specialist visited both schools three times a week for three months. Always in the presence of the class tutor, the intervention was carried out in 45-minute class sessions, following a three-step procedure: (1) students were presented with the intervention tool on a digital board, were shown the images and pictograms used in the iconic representation, were given examples and were then allowed to do some practice with the tool; (2) all students, working individually and simultaneously on their computers, completed two Hypertextos under the specialist's supervision; (3) Hypertextos were produced on the digital board in a sequential order throughout the three-month period so that all the students were able to do the revision process.

While the tool was being implemented with the EG, teachers in the CG continued with their habitual methodology, oriented toward the curricular competencies set for this educational stage. In particular, worksheets with various tasks were used: identifying the size of objects, identifying letters of the alphabet, colouring, tracing, or pasting on images related to themes such as the seasons or means of transport, and copying from a picture. Teachers would present and revise the activities collectively and guide individual work. A specialist collaborating with the project visited the classes every week so as to observe and register the activities implemented by the teachers, ensuring the same work dynamics were used in both classes. Both groups were subject to posttest evaluation at the end of the intervention process.

2.5. Data Analysis. Taking into account the objectives of the study, data analyses were conducted in three steps. Firstly, the descriptive statistics for the variables under study were analyzed, paying special attention to skewness and kurtosis. As a second step, Univariate (ANOVA) and Multivariate (MANOVA) Analyses of Variance were carried out in order to analyze the differences between the groups (EG and CG) in the dependent variables (posttest measures of verbal aspects-Peabody-and psycholinguistic aspects-ITPA). Age, school year, sex, and pretest measures showed no statistically significant differences between the groups, so these variables were not included as covariates. Finally, with the aim of testing the effectiveness of the tool according to school years (years $1 \& 2$ of Primary Education), differences were analyzed between the first and second years of Primary Education (ANOVA and MANOVA).

\section{Results}

Table 1 provides descriptive statistics for the variables included in the analysis (mean and standard deviation). 

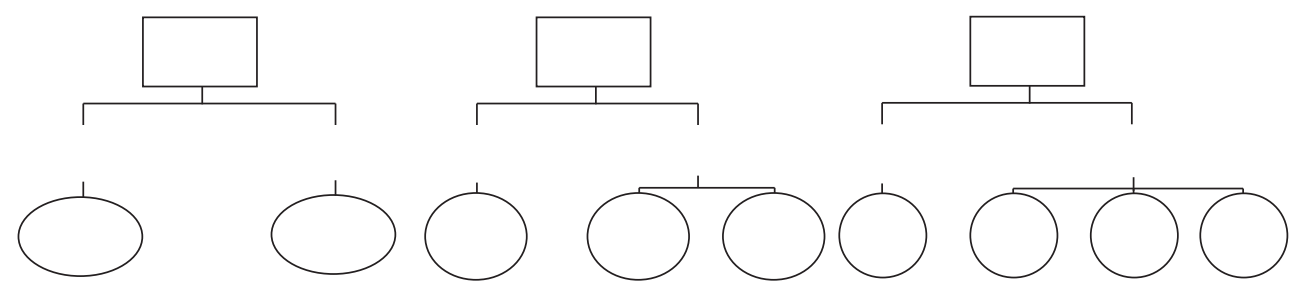

FIgURE 2: Example of Hypertexto structures, in which students select, relate, and transmit the information.

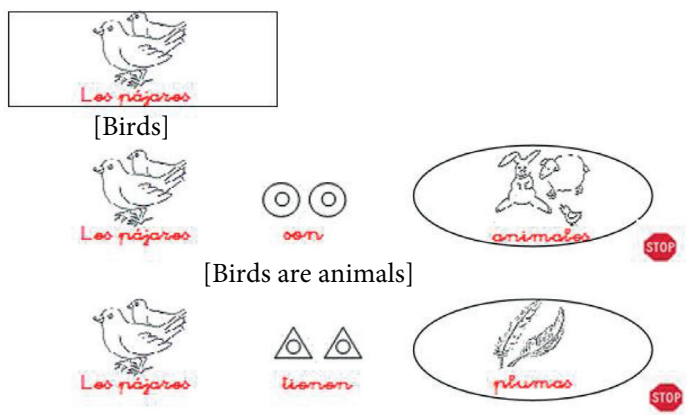

The activity starts with a linear

message. In this example,

combined representation is

used.

[Birds have feathers]

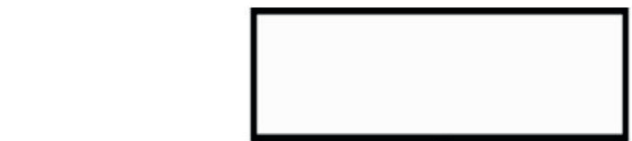

Students have to place all the elements of the linear message in the hypertexto.
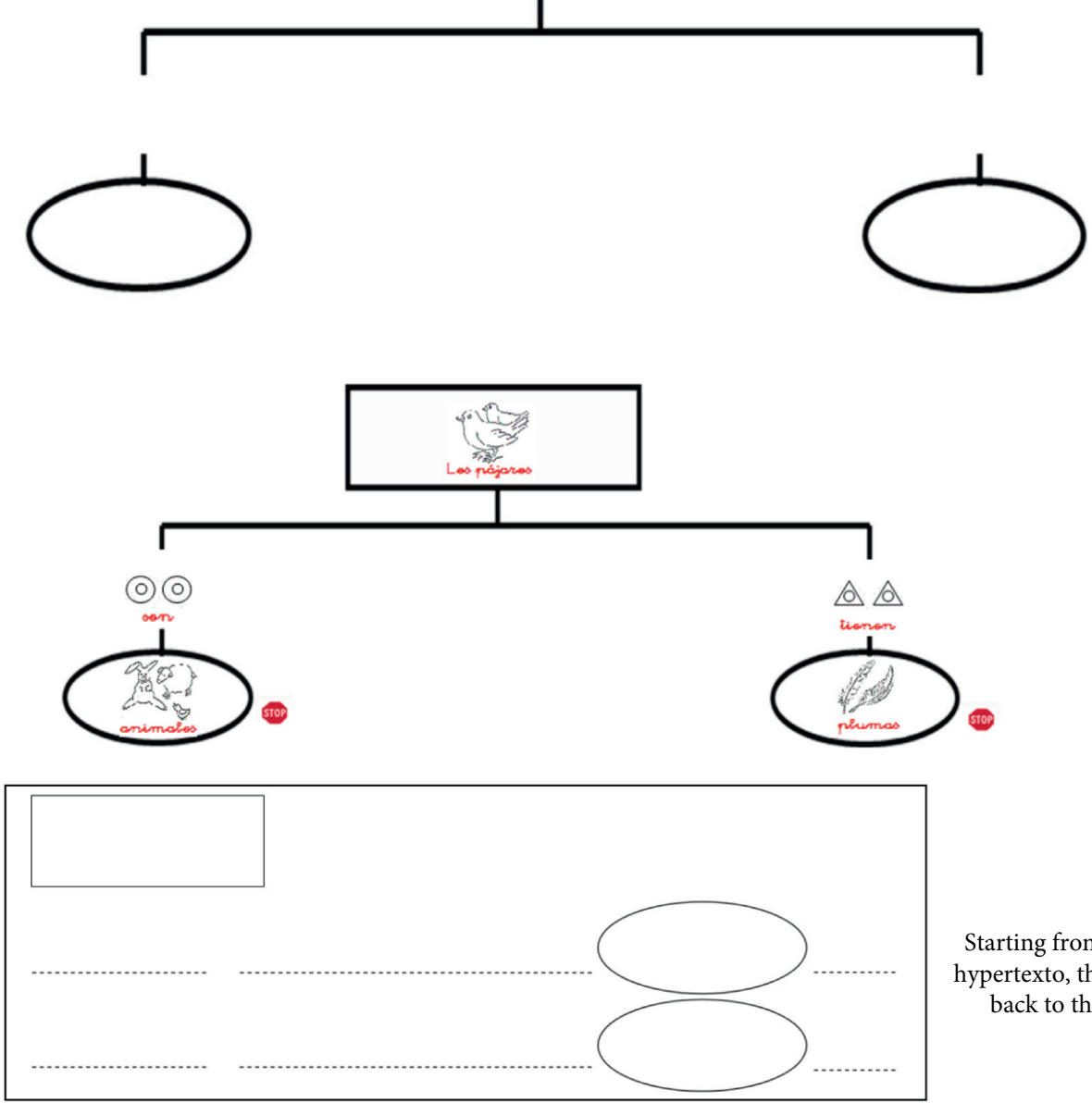

Starting from the resulting hypertexto, the students step back to the linear text.

FIgURE 3: Example of an activity in the program EPI.com: children have to organize the information of the linear message into the Hypertexto and subsequently convert it back into linear text. 
According to the skewness and kurtosis values, univariate normality is observed in the variables of interest (values lower than 3 for skewness and lower than 10 for Kurtosis; [34]). Skewness values for the pretest variables reached scores ranging between -0.525 and 0.632 , and for the posttest variables between -0.516 and 0.598 . Regarding Kurtosis, the scores were situated between -1.156 and -0.073 for the pretest and between -1.134 and -0.535 for the posttest.

Differences in the pretest were no statistically significant, neither in the verbal aspects (Peabody) $F(1,60)=$ $0.500, p=0.482, \eta_{p}^{2}=0.008$, nor in the psycholinguistic aspect (ITPA) Wilks $\lambda=0.703, F(11,50)=1.920, p=0.059$, $\eta_{p}^{2}=0.297$. These variables were not included as a covariate in the subsequent analyses.

With regard to posttest scores, differences were not statistically significant between the groups (EG and CG) in verbal aspects, (Peabody) $F(1,60)=3.711, p=0.059$, $\eta_{p}^{2}=0.058$. However, differences were statistically significant in psycholinguistic aspects (ITPA) Wilks' $\lambda=.0 .291, F(11$, $50)=11.083, p \leq 0.001, \eta_{p}^{2}=0.709$ with a large effect size. Specifically, Table 1 shows that these differences were found in all variables except Auditory Comprehension $(p=0.082)$, Auditory Association $(p=0.062)$, Motor Expression $(p=0.106)$, and Auditory Integration $(p=0.132)$. As for the sizes of effect, the variables with the greatest explanatory value were Grammatical Integration, Verbal Expression, Visual Association, and Verbal Integration.

3.1. School-Year-Based Profiles. The investigation also aimed at testing the effectiveness of the tool according to school years (years $1 \& 2$ of Primary Education), mainly because EPI.com is a tool aimed at students in different age groups and introduces content in a progressive and sequential way, arranging them into levels according to their developmental stage. The results are provided in Table 2.

In relation to Group 1 (Year 1), differences between the EG $(n=18)$ and the CG $(n=12)$ were not statistically significant in the Peabody test $(p=0.430)$. Statistically significant variables were found in the ITPA, Wilks' $\lambda=.247, F$ $(11,18)=6.189, p \leq 0.001, \eta_{p}^{2}=0.753$ with a large effect size (see Table 2). More specifically, differences were significant in the variables Visual Association, Verbal Expression, and Grammatical Integration.

With regard to Group 2, (Year 2), the differences found between the EG $(n=20)$ and the CG $(n=12)$ were not significant in the Peabody variable $(p=0.8433)$. Statistically significant variables were found in the ITPA, Wilks' $\lambda=0.225, F(11,20)=6.246, p \leq 0.001, \eta_{p}^{2}=0.775$ (again with a large effect size) in the variables Verbal Expression and Grammatical Integration.

\section{Discussion}

This piece of work aimed at stimulating psycholinguistic aspects in students in years 1 and 2 of Primary Education in Spain by means of the strategy EPI.com. Two specific objectives were set: (a) analyzing the benefits brought by the strategy onto psycholinguistic and verbal aspects as compared to those associated with traditional methods; (b) analyzing the benefits according to school years (years 1 \& 2 of Primary Education).

The hypothesis raised was partially confirmed. Results showed that the strategy was effective in improving those psycholinguistic aspects measured by the ITPA. Benefits were greater in the variable Grammatical Integration, relating to syntactic processing and requiring identification abilities and usage of grammar structure. Benefits were greater also in Verbal Expression, Visual Association, and Visual Integration; those variables were more closely linked to lexical processing.

Grammatical Integration and Visual Association were the variables with the greatest explanatory value. Since a key aspect of the tool is the stimulation of syntactic processing through expression and the management of text structure, a positive evolution was seen after the intervention in variables evaluated through tasks like completing sentences, rhymes, or riddles. Likewise, variables such as Verbal Expression and Visual Integration showed a more significant difference than the rest. In this case, both Verbal Expression and Visual Integration might be more closely linked to lexical processing since they require abilities such as expressing concepts, verbal fluency, or pointing at objects within a given category. Previous studies have shown that organizers of knowledge like the Hypertexto, allow improving psycholinguistic aspects like lexical, syntactic, and semantic processes (e.g., [12, 18-22]). Most of these studies have been focused on comprehension, or semantic processing, rather than on other aspects like syntactic or lexical processing. In the present study, in which all these three main processes have been considered, we could see that the variables in which improvement is more evident are those associated with syntactic and lexical aspects. As was pointed by Nesbit and Adesope [22], students who use concept maps may be better able to identify the internal connections among concepts presented in texts.

All in all, the strategy, based on Mayer's SOI model [10], is structured into selecting, organizing, and integrating, so that the sequence allows for the identification of keywords and their meanings (lexical processing), for the expression and management of adequate grammar structure (syntactic processing), and for the relation of main ideas in order for the global meaning of a text to be grasped (semantic processing). Since this is a structurebased strategy, students who have been using it have shown improvement in lexical and syntactic processing.

As stated by Mayer [10], the process leading to learning depends both on the way students process information and on the materials being presented to them. In this sense, the usage of the computerized strategy is relevant and may be fostering positive achievements. Authors like Sung et al. [26] have pointed out that the difficulties found when applying reading learning strategies in the classroom may be reduced with the aid of Information Technology.

On the other hand, other variables were not significant, as is the case with Auditory Comprehension, Auditory 
TABle 1: Descriptive statistics and differences between the two groups (EG and CG) in the posttest.

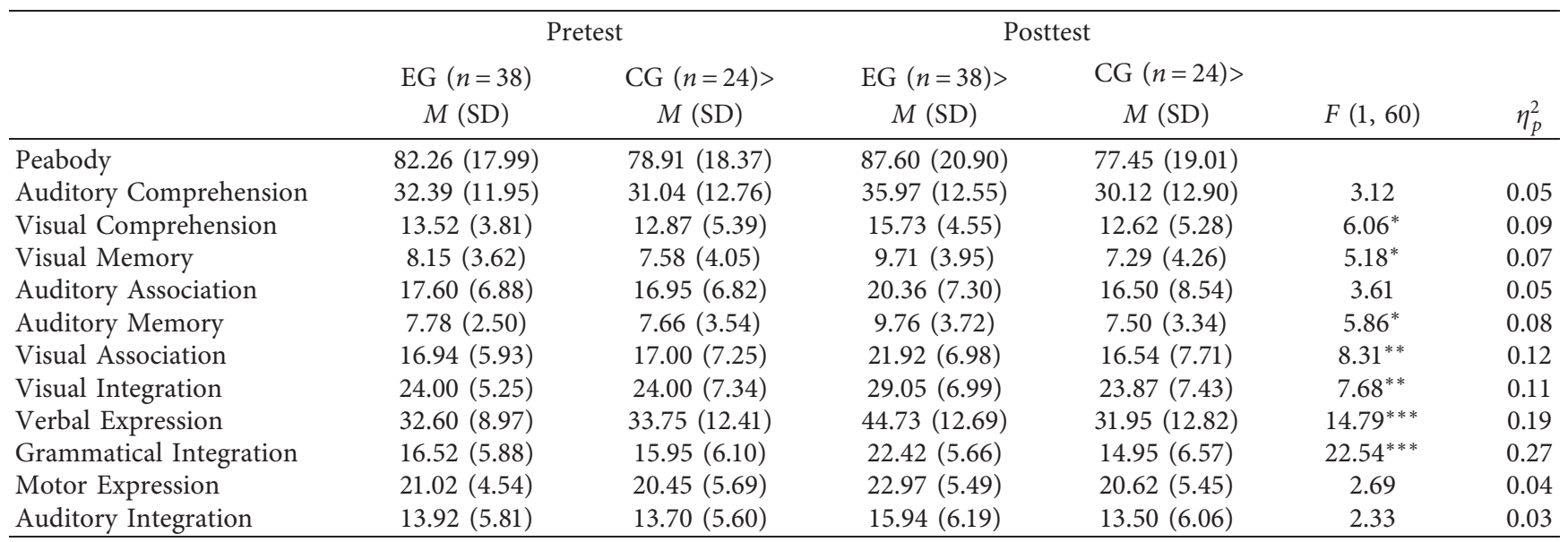

Note. $M=$ Mean, $\mathrm{SD}=$ Standard Deviation, $\mathrm{EG}=$ Experimental Group, $\mathrm{CG}=$ Control Group. Following the effect sizes Cohen [33] criterion, the effect is small when $\eta_{p}^{2}<0.01$, average when $\eta_{p}^{2} \geq 0.59$, and large when $\eta_{p}^{2} \geq 1.38$. ${ }^{*} p<0.05,{ }^{* *} p<0.01,{ }^{* * *} p<0.001$.

TABLE 2: Results of the differences between the two age groups.

\begin{tabular}{|c|c|c|c|c|c|c|c|c|}
\hline & \multicolumn{4}{|c|}{ Group 1} & \multicolumn{4}{|c|}{ Group 2} \\
\hline & $\begin{array}{c}\mathrm{EG} \\
M(\mathrm{SD})\end{array}$ & $\begin{array}{c}\text { CG } \\
M(\mathrm{SD})\end{array}$ & $F(1,28)$ & $\eta_{p}^{2}$ & $\begin{array}{c}\mathrm{EG} \\
M(\mathrm{SD})\end{array}$ & $\begin{array}{c}\text { CG } \\
M(\mathrm{SD})\end{array}$ & $F(1,30)$ & $\eta_{p}^{2}$ \\
\hline Peabody & $76.16(17.34)$ & $71.41(13.36)$ & 0.643 & 0.022 & $87.75(17.15)$ & $86.41(20.12)$ & 0.040 & 0.001 \\
\hline Auditory Comprehension & $33.72(12.15)$ & $26.00(14.18)$ & 2.54 & 0.083 & $38.00(12.86)$ & $34.25(10.48)$ & 0.72 & 0.024 \\
\hline Visual Comprehension & $14.00(4.48)$ & $10.91(4.73)$ & 3.25 & 0.104 & $17.30(4.11)$ & $14.33(5.43)$ & 3.06 & 0.093 \\
\hline Visual Memory & $8.27(3.02)$ & $6.16(3.61)$ & 3.00 & 0.097 & $11.00(4.30)$ & $8.41(4.71)$ & 2.51 & 0.077 \\
\hline Auditory Association & $18.72(6.45)$ & $14.25(6.15)$ & 3.58 & 0.114 & $21.85(7.86)$ & $18.75(10.18)$ & 0.93 & 0.030 \\
\hline Auditory Memory & $8.61(3.39)$ & $6.75(2.92)$ & 2.40 & 0.079 & $10.80(3.77)$ & $8.25(3.69)$ & 3.47 & 0.104 \\
\hline Visual Association & $20.05(6.32)$ & $14.66(5.61)$ & $5.69^{*}$ & 0.169 & $23.60(7.27)$ & $18.41(8.71)$ & 3.28 & 0.099 \\
\hline Visual Integration & $26.38(7.07)$ & $21.50(5.90)$ & 3.90 & 0.122 & $31.45(6.13)$ & $26.25(8.26)$ & 4.14 & 0.121 \\
\hline Verbal Expression & $40.22(10.95)$ & $27.16(9.84)$ & $11.06^{* *}$ & 0.283 & $48.80(13.02)$ & $36.75(14.02)$ & $6.06^{*}$ & 0.168 \\
\hline Grammatical Integration & $20.72(5.00)$ & $13.33(5.36)$ & $14.82^{* *}$ & 0.346 & $23.95(5.90)$ & $16.58(7.46)$ & $9.57^{* *}$ & 0.242 \\
\hline Motor Expression & $21.38(5.03)$ & $19.25(4.35)$ & 1.44 & 0.049 & $24.40(5.63)$ & $22.00(6.26)$ & 1.25 & 0.040 \\
\hline Auditory Integration & $14.61(6.11)$ & $12.50(5.28)$ & 0.96 & 0.033 & $17.15(6.20)$ & $14.50(6.84)$ & 1.26 & 0.041 \\
\hline
\end{tabular}

Note. $M=$ Mean, $\mathrm{SD}=$ Standard Deviation, Group $1=$ year 1 of Primary Education, Group $2=$ year 2 of Primary EG= Experimental Group, CG =Control Group. Following the effect sizes Cohen [33] criterion, the effect is small when $\eta_{p}^{2}<0.01$, average when $\eta_{p}^{2} \geq 0.59$, and large when $\eta_{p}^{2} \geq 1.38$. ${ }^{*} p<0.05$, ${ }^{* *} p<0.01,{ }^{* * *} p<0.001$.

Association, Motor expression, and Auditory Integration. Those are variables that are more closely related to the capacity to obtain or relate the meaning of orally presented information or to express meaning through gesture. Since the strategy is globally applied in a written form, and despite the fact that there is an initial oral reading task, it appears to be reasonable to think that results will not be outstanding nor significant at this level.

Regarding the benefits according to school years (years 1 \& 2 of Primary Education), we could observe that in group 1 (first year), the effect sizes reflected higher differences between the EG and the CG than in group 2 (second year). In this sense, Nesbit and Adesope [22] show that low-ability students or students with low verbal ability obtain benefit more from interventions based on conceptual maps than high-ability learners do. In relation to the present study, students in Year 1 are more likely to have a lower verbal ability for developmental reasons and, among them, there would also be greater room for improvement, as they have a lower starting point in terms of abilities. This fact could explain why students in the first year reach better results than those in Year 2.

\section{Conclusions}

By way of conclusion, we must finally highlight the need for interventions aimed at favoring maturation in some key aspects at early ages. In teaching to read, a large amount of effort is set on the mechanics of the process in order for children to get to an adequate articulation and encouraging phonological awareness mainly. At later stages, as school-age increases, significant failure can be observed in comprehension, thus the relevance of implementing these interventions that will set the basis for future learning.

Some limitations of the present study that should be addressed in future work must be highlighted at this point. 
First, as for the program used, it would be convenient to carry out an evaluation of the steps taken by students during the execution of the program. Besides, there seems to be a need for some more specific testing of processing types, including reading comprehension so as to determine evolution at that level in a more specific manner.

Finally, in future work, it would be interesting to analyze the benefits brought about by the tool as related to the students' previous levels. As was indicated above, Nesbit and Adesope [22] reflected that students with low verbal ability benefit more from interventions based on conceptual maps. Besides, it would be interesting to analyze the effects of the program on students with specific learning difficulties, attention-deficit/hyperactivity disorder, or specific language impairment, among whom authors like Acosta-Rodríguez et al. [35] have detected low levels in the ITPA scores.

\section{Data Availability}

Data are available upon request.

\section{Conflicts of Interest}

The authors declare that there are no conflicts of interest regarding the publication of this paper.

\section{Acknowledgments}

This work was funded by the $\mathrm{I}+\mathrm{D}+\mathrm{i}$ project (Ministry of Science, Innovation and Universities) with reference no. PGC2018-097739-B-I00 and the regional project (Government of the Principality of Asturias) with reference no. FCGRUPIN-IDI/2018/000199.

\section{References}

[1] M. Psyridou, A. Tolvanen, M.-K. Lerkkanen, A.-M. Poikkeus, and M. Torppa, "Longitudinal stability of reading difficulties: examining the effects of measurement error, cut-offs, and buffer zones in identification," Frontiers in Psychology, vol. 10, p. e2841, 2020.

[2] N. Calet, R. López-Reyes, and G. Jiménez-Fernández, "Do reading comprehension assessment tests result in the same reading profile? A study of Spanish primary school children," Journal of Research in Reading, vol. 43, no. 1, pp. 98-115, 2020.

[3] Ministerio de Educación y Formación Profesional, PISA Report 2018. Program for International Student Assessment: Spanish Report (Preview Version), Secretaría General Técnica, Madrid, Spain, 2019.

[4] Ministerio De Educación Cultura, PIRLS 2016 Progress in International Reading Literacy Study. Spanish Report, Secretaría General Técnica, Madrid, Spain, 2017.

[5] E. J. Tyler, J. C. Hughes, M. Beverley, and R. P. Hastings, "Improving early reading skills for beginning readers using an online programme as supplementary instruction," European Journal of Psychology of Education, vol. 30, no. 3, pp. 281-294, 2015.

[6] L. Aráujo and P. Costa, "Home book reading and reading achievement in EU countries: the progress in international reading literacy study 2011 (PIRLS)," Educational Research and evaluation: An International Journal on Theory and Practice, vol. 21, no. 5-6, pp. 422-438, 2015.
[7] D. R. Petretto and C. Masala, "Dyslexia and specific learning disorders: new international diagnostic criteria," Journal of Childhood and Developmental Disorders, vol. 3, no. 4, p. e19, 2017.

[8] American Psychiatric Association, Diagnostic and Statistical Manual of Mental Disorders, American Psychiatric Publishing, Arlington, VA, USA, 5th edition, 2013.

[9] F. V. Lirola, "Specific Educational Support Needs: prevalence rate and retrospective analysis," Revista Nacional e Internacional de Educación Inclusiva, vol. 12, no. 2, pp. 66-77, 2019.

[10] A. Doganay-Bilgi, "Evaluating the effect of parent reading interventions on improving reading fluency of students with reading difficulties," Behavioral Interventions, vol. 35, no. 2, pp. 217-233, 2020.

[11] R. E. Mayer, Learning and Instruction, Pearson Merrill Prentice Hall, Upper Saddle River, NJ, USA, 2nd edition, 2008.

[12] H. R. Ponce, M. J. López, and R. E. Mayer, "Instructional effectiveness of a computer-supported program for teaching reading comprehension strategies," Computers \& Education, vol. 59, no. 4, pp. 1170-1183, 2012.

[13] S. M. R. Watson, R. A. Gable, S. B. Gear, and K. C. Hughes, "Evidence-Based strategies for improving the reading comprehension of secondary students: implications for students with learning disabilities," Learning Disabilities Research \& Practice, vol. 27, no. 2, pp. 79-89, 2012.

[14] H. L. Swanson, C. B. Howard, and L. Sáez, "Do different components of working memory underlie different subgroups of reading disabilities?" Journal of Learning Disabilities, vol. 39, no. 3, pp. 252-269, 2006.

[15] S. Ghahari and M. Basanjideh, "Dynamics of strategies-based language instruction: a study of reading comprehension and problem solving abilities via structural equation modeling," RELC Journal, vol. 46, no. 3, pp. 237-253, 2015.

[16] L. Álvarez and E. Soler, I Understand with Hypertexto, Cepe, Madrid, Spain, 2005.

[17] D. P. Ausubel, J. D. Novak, and H. Hanesian, Educational Psychology: A Cognitive View, Holt, Rinehart and Winston, New York, NY, USA, 2nd edition, 1978.

[18] J. Gurlitt and A. Renkl, "Prior knowledge activation: how different concept mapping tasks lead to substantial differences in cognitive processes, learning outcomes, and perceived selfefficacyficacy," Instructional Science, vol. 38, no. 4, pp. 417-433, 2010.

[19] D. W. Moore and J. F. Readence, "A quantitative and qualitative review of graphic organizer research," Journal of Educational Research, vol. 78, pp. 11-17, 1984.

[20] I. İlter, "The power of graphic organizers: effects on students' word-learning and achievement emotions in social studies," Australian Journal of Teacher Education, vol. 41, no. 1, pp. 42-64, 2016.

[21] A.-H. Kim, S. Vaughn, J. Wanzek, and S. Shangjin Wei, "Graphic organizers and their effects on the reading comprehension of students with LD," Journal of Learning Disabilities, vol. 37, no. 2, pp. 105-118, 2004.

[22] J. C. Nesbit and O. O. Adesope, "Learning with concept and knowledge maps: a meta-analysis," Review of Educational Research, vol. 76, no. 3, pp. 413-448, 2006.

[23] M. D. Gil and C. Vicent, "Comparative analysis of the efficacy of a playful-narrative program to teach mathematics at preschool level," Psicothema, vol. 21, no. 1, pp. 70-75, 2009. 
[24] L. Álvarez and P. González-Castro, Reinforcement Program to Stimulate Thinking and Intelligence EPI.com, EOS, Madrid, Spain, 2012.

[25] M. Cueli, C. Rodríguez, A. I. Álvarez, D. Areces, and P. González-Castro, "Eficacia del programa informatizado EPI.com para la mejora de la comprensión y la expresión de estudiantes de entre 3 y 6 años," Revista de Psicodidáctica, vol. 22, no. 2, pp. 128-134, 2017.

[26] Y.-T. Sung, K.-E. Chang, and J.-S. Huang, "Improving children's reading comprehension and use of strategies through computer-based strategy training," Computers in Human Behavior, vol. 24, no. 4, pp. 1552-1571, 2008.

[27] P. G. Mathes, J. K. Torgesen, and J. H. Allor, "The effects of peer-assisted literacy strategies for first-grade readers with and without additional computer-assisted instruction in phonological awareness," American Educational Research Journal, vol. 38, no. 2, pp. 371-410, 2001.

[28] J. Raven, J. C. Raven, and J. H. Court, Manual for Raven's Progressive Matrices and Vocabulary Scales. The Standard Progressive Matrices, TEA Editions, Madrid, Spain, 2000.

[29] S. Ballesteros and A. Cordero, Spanish adaptation of the Illinois test of Psycholinguistic Abilities, TEA Editions, Madrid, Spain, 2011.

[30] S. Kirk, J. McCarthy, and W. Kirk, The Illinois Test of Psycholinguistic Abilities, TEA Editions, Madrid, Spain, 1986.

[31] Ll. M. Dunn, L. M. Dunn, and D. Arribas, Peabody Picture Vocabulary Test, TEA Editions, Madrid, Spain, 2010.

[32] R. P. McDonald, Test Theory: A Unified Treatment, Lawrence Erlbaum Associates, Inc., Mahwah, NJ, USA, 1999.

[33] J. Cohen, Statistical Power Analysis for the Behavioral Sciences, Erlbaum, Hillsdale, NJ, USA, 2nd edition, 1988.

[34] R. B. Kline, Principles and Practice of Structural Equation Modelling, Guilford Press, New York, NY, USA, 2011.

[35] V. M. Acosta-Rodríguez, G. M. Ramírez-Santana, N. del Valle Hernández, and L. de Castro Bermúdez, "Intervention in reading processes in pupils with specific language impairment (SLI)," Psicothema, vol. 28, no. 1, pp. 40-46, 2016. 